\title{
Improving SERS Detection of Bacillus thuringiensis Using Silver Nanoparticles Reduced with Hydroxylamine and with Citrate Capped Borohydride
}

\author{
Hilsamar Félix-Rivera, ${ }^{1}$ Roxannie González, ${ }^{1}$ Gabriela Del Mar Rodríguez, ${ }^{1}$ \\ Oliva M. Primera-Pedrozo, ${ }^{1}$ Carlos Ríos-Velázquez, ${ }^{2}$ and Samuel P. Hernández-Rivera ${ }^{1}$ \\ ${ }^{1}$ Department of Chemistry, ALERT-DHS Center of Excellence, Center for Chemical Sensors Development, \\ University of Puerto Rico-Mayagüez, P.O. Box 9000, Mayagüez, PR 00681-9000, Puerto Rico \\ ${ }^{2}$ Microbial Biotechnology and Bioprospecting Laboratory, Department of Biology, University of Puerto Rico-Mayagüez, \\ P.O. Box 9000, Mayagüez, PR 00681-9000, Puerto Rico
}

Correspondence should be addressed to Oliva M. Primera-Pedrozo, olivaprimera@yahoo.es

Received 1 May 2011; Accepted 14 June 2011

Academic Editor: Ahmed Aamouche

Copyright (C) 2011 Hilsamar Félix-Rivera et al. This is an open access article distributed under the Creative Commons Attribution License, which permits unrestricted use, distribution, and reproduction in any medium, provided the original work is properly cited.

The development of techniques that could be useful in fields other than biological warfare agents countermeasures such as medical diagnostics, industrial microbiology, and environmental applications have become a very important subject of research. Raman spectroscopy can be used in near field or at long distances from the sample to obtain fingerprinting information of chemical composition of microorganisms. In this research, biochemical components of the cell wall and endospores of Bacillus thuringiensis (Bt) were identified by surface-enhanced Raman scattering (SERS) spectroscopy using silver (Ag) nanoparticles (NPs) reduced by hydroxylamine and borohydride capped with sodium citrate. Activation of "hot spots", aggregation and surface charge modification of the NPs, was studied and optimized to obtain signal enhancements from Bt by SERS. Slight aggregation of the NPs as well as surface charge modification to a more acidic ambient was induced using small-size borohydride-reduced NPs in the form of metallic suspensions aimed at increasing the Ag NP-Bt interactions. Hydroxylamine-reduced NPs required slight aggregation and no $\mathrm{pH}$ modifications in order to obtain high spectral quality results in bringing out SERS signatures of $B t$.

\section{Introduction}

Bioterrorism's high potential for destruction has become a subject of great concern. Fast, efficient, and inexpensive detection techniques for microorganisms have become a very important subject in areas of national defense and homeland security. Techniques such as conventional Raman spectroscopy (RS) and surface-enhanced Raman scattering (SERS) require a minimum amount of sample for a fast detection [1] so that they can be implemented in near field or at long distances from the sample by obtaining fingerprinting information of the chemical composition of microorganisms. The time required for identification of pathogens is a determinant factor of infection related sickness. The development of these techniques could be useful in fields other than biological warfare agents countermeasures such as medical diagnostics [2], industrial microbiology [3], and environmental applications [4].

Bacillus thuringiensis (Bt), a Gram-positive bacterium, is widely renowned for its toxicity on insect larvae and is commercially used as insecticide. Bt, as a bacillus species, has a bacterial life cycle in which it grows as vegetative cell forming endospores as defense mechanism. The bacterial cell wall contains a peptidoglycan layer responsible for strengthening the wall. This rigid layer in a Gram-positive species cell wall is typically much ticker. The peptidoglycan layer contains alternating repeats of $\mathrm{N}$-acetylglucosamine (NAG) 
and $\mathrm{N}$-acetylmuramic (NAM) acid. It encloses a group of molecules called teichoic and lipoteichoic acids, which are unique to Gram-positive bacteria cell wall. Bt produces a crystalline protein during sporulation called parasporal body that is converted to a toxin by proteolytic cleavage in the larval gut.

Endospores are able to tolerate extreme environments, thus making them suitable for transporting before or during a biological attack. The bacterial endospores contain several well-known layers, from internal to external location. Among these are the cortex, the core wall, the spore coat, and the exosporium. Biochemical components of these layers include sugar chains, short peptides of peptidoglycan, polypeptides, fatty acids (lipids), carbohydrates, and proteins. In the core, thick layer of proteins, dipicolinic acid, and calcium ions normally exist in the form of a calcium-dipicolinate complex that stabilize and protect the genetic material of the endospore [5-7]. Biological samples as virus [8], pollen [9], essential components of bacterial cell wall, and bacterial endospores have been studied by SERS effect using Ag or $\mathrm{Au}$ metallic colloids to optimize procedures for detection, identification, and classification.

Citrate-reduced nanoparticles (NPs) have been widely used to classify and discriminate spores of different species by principal component analysis (PCA) of SERS spectra [10]. On the other hand, borohydride-reduced NPs have allowed Bacillus subtilis discrimination using SERS [11]. To increase the electrostatic interaction between the surfaces of the NPs with the bacterial cell-wall modifications to the surface charge of the NPs can be made, depending on the reducing agent of the metallic ions solutions [12]. Ag-borohydride NPs were modified by changing the $\mathrm{pH}$ of the colloid to obtain a more intimate interaction with the bacterial cell wall in which at low and high $\mathrm{pH}$ values (3.25 and 9.74) did not result in improved detection of Escherichia coli $[13,14]$. Improved SERS signals at $\mathrm{pH}$ of 5 and higher were obtained for Bacillus Gram-positive species with citrate reduced nanoparticles [15] and for biological molecules with amine groups using hydroxylamine hydrochloride-reduced NPs [16]. The changes in NPs surfaces increase the formation of hot spots and consequently further augment of SERS effect that can be observed. To induce aggregation, $\mathrm{pH}$ changes as well as adding halide anions to the nanoparticles can also be used. The use of aggregation agents in SERS of bacterial samples was studied to allow the NPs-induced aggregation and to generate highly SERS-active interparticle spaces [17]. Bacillus thuringiensis detection has been studied by SERS using silver oxide films [18], Au NPs covered by $\mathrm{SiO}_{2}$ [19], Ag colloids reduced by citrate [10] and by hydroxylamine hydrochloride [20]. However, Bt interaction with Ag-NPs capped with citrate and the optimization of the NPs to increase the SERS signals has not been reported in the literature.

The reproducibility and consistency of enhancement of vibrational signatures of microorganisms and their stability and dependence on morphology of SERS active substrates has also been studied in depth [19]. It is well known that the electromagnetic and chemical mechanisms of SERS produced by NPs upon interaction with analytes is in general determined by the intimacy of the interaction of the molecules to the surface plasmon field and the charge transfer at the "hot spots" sites. The optimization procedure for achieving maximum signals played an important role in the attainment of high Raman enhancements for $B t$. Since no specific studies addressing these important issues of $B t$ using these sensing platforms were found, it was decided to study them.

\section{Experimental Section}

2.1. Materials. Silver nitrate $\left(\mathrm{AgNO}_{3}, 99+\%\right)$, sodium borohydride $\left(\mathrm{NaBH}_{4}, 98 \%\right)$, hydroxylamine hydrochloride $\left(\mathrm{NH}_{2} \mathrm{OH} \cdot \mathrm{HCl}\right)$, trisodium citrate dihydrate $\left(\mathrm{Na}_{3} \mathrm{C}_{6} \mathrm{H}_{5} \mathrm{O}_{7}\right.$. $2 \mathrm{H}_{2} \mathrm{O}$ ), sodium chloride $(\mathrm{NaCl}, 99.9+\%)$ and sodium hydroxide $(\mathrm{NaOH})$ were acquired from Sigma-Aldrich Chemical Co., (Milwaukee, WI). Nanopure deionized ultra high purity water (UHP; $18.2 \mathrm{M} \Omega-\mathrm{cm}$ ) was used for the preparation of aqueous metal ions solutions. Glassware was cleaned by soaking in aqua regia and finally washing with distilled and deionized water several times. Bt strain (ATCC no. 35646) was provided by the Microbial Biotechnology and Bioprospecting Lab, Biology Department, UPRM. It was grown using Miller modified Luria-Bertani (LB) agar and broth (Fisher Scientific International; Thermo Fisher Scientific, Waltham, Mass, USA).

2.2. Preparation of Ag-NPs. Borohydride reduced Ag-NPs were prepared using the method of Keir, Sadler and Smith [21] using $1 \mathrm{~mL}$ of $1 \%$ sodium citrate. The method was modified by using citrate as capping agent to avoid colloidal precipitation. A typical synthesis consisted of dissolving $3.4 \mathrm{mg}$ of $\mathrm{NaBH}_{4}$ in $75 \mathrm{~mL}$ of UHP water that had been previously degasified with $\mathrm{N}_{2}$ and cooled at $4^{\circ} \mathrm{C}$ under vigorous stirring using rotating magnetic bar. Then, $1 \mathrm{~mL}$ of trisodium citrate was added to the flask. Finally, $9 \mathrm{~mL}$ of $\mathrm{AgNO}_{3} 0.0022 \mathrm{M}$ was added at a rate of $20.5 \mu \mathrm{L} / \mathrm{s}$ and stirred for $45 \mathrm{~min}$. Hydroxylamine-reduced Ag colloids were prepared by the method of Leopold and Lendl [22] by dissolving $10.44 \mathrm{mg}$ of hydroxylamine in UHP water $(1.67 \times$ $10^{-3} \mathrm{M}$ ) and $11.98 \mathrm{mg}$ of $\mathrm{NaOH} 3.33 \times 10^{-3} \mathrm{M}$ in UHP water and $90 \mathrm{~mL}$ of pure degasified water for $15 \mathrm{~min}$ while stirring with a magnetic bar. Then, $10 \mathrm{~mL}$ of $1.0 \times 10^{-2} \mathrm{M}$ silver nitrate solution was added dropwise with constant nitrogen bubbling. Colloidal suspensions at different $\mathrm{pH}$ values were prepared using 0.1 and $0.01 \mathrm{M}$ of both $\mathrm{HCl}$ and $\mathrm{NaOH}$ and the measurements were read using a $\mathrm{pH}$ meter.

2.3. Preparation of Bacterial Sample. Pure culture of Bt stored at $-80^{\circ} \mathrm{C}$ in $20 \%$ glycerol was inoculated in LB agar plates and incubated at $32^{\circ} \mathrm{C}$ overnight. After transferring pure culture to $5.0 \mathrm{~mL} \mathrm{LB}$ broth in a culture tube, it was placed in an orbital shaker at $32^{\circ} \mathrm{C}(\sim 120 \mathrm{rpm})$ during $24 \mathrm{hr}$. An Erlenmeyer flask $(250 \mathrm{~mL})$ was prepared with nutrient media and microorganism culture to a final volume of $25 \mathrm{~mL}$ to obtain an initial optical density at $600 \mathrm{~nm}\left(\mathrm{OD}_{600}\right)$ of 0.025 . Samples were collected after bacteria were cultured for $15 \mathrm{hr}$ then centrifuged for $12 \mathrm{~min}$ at $8228 \mathrm{rcf}$ and the supernatant 
was discarded. The pellet obtained was washed twice with $5 \mathrm{~mL}$ of $0.1 \mathrm{M} \mathrm{NaCl}$ and finally resuspended in $0.1 \mathrm{M} \mathrm{NaCl}$. The bacterial concentration used was $10^{7} \mathrm{cfu} / \mathrm{mL}$, and the $\mathrm{OD}_{600}$ (Biophotometer, Eppendorf) was measured before and after centrifugation. The bacterial samples were stored at $4^{\circ} \mathrm{C}$ until experiments were performed. Standard Biosafety Level 2 procedures were employed to handle, process, and discard the samples. Techniques such as Gram stain and Fulton-Schaeffer spore stain were used to characterize Bt.

2.4. Raman and SERS Sample Preparation. Bacterial samples were transferred to glass capillary tubes $(1.5 \times 90 \mathrm{~mm})$ using sterile, disposable needles and syringes to obtain the Raman spectra. A small amount of the bacterial solution dissolved in $0.1 \mathrm{M} \mathrm{NaCl}$ was used for normal Raman experiments. For SERS experiments, $200 \mu \mathrm{L}$ of colloidal NPs suspensions (as prepared) were mixed with $25 \mu \mathrm{L}$ of bacterial suspension in a microcentrifuge tube and vigorously shaken in a minivortex. Small amounts of the mixtures were transferred to the capillary tubes and SERS spectra were obtained. To further increase Raman signals by stimulation of formation of hot spots on aggregation of NPs, clustering was promoted by addition of $1.0 \mathrm{M} \mathrm{NaCl}$ to colloidal suspensions [23]. To adjust the $\mathrm{pH}$ values of colloidal suspensions, small amounts of $\mathrm{HCl}$ and $\mathrm{NaOH}$ with concentration of 0.01 or $0.1 \mathrm{M}$ were added until obtaining the desired $\mathrm{pH}$ ( 1 to 13 ). Then, the mixtures were prepared for SERS experiments using the same procedure as described.

\section{Measurements and Analysis}

3.1. Instrumentation. Ag-Nps were characterized by UV-VIS spectrophotometry and by transmission electron microscopy (TEM). Absorption spectra of the solutions were acquired using a Cary 5000 UV-VIS-NIR spectrophotometer (Varian, Palo Alto, Calif, USA). TEM images were recorded by in a model 1011 electron transmission microscope providing a resolution of $0.2 \mathrm{~nm}$ lattice with magnification of 50 to $10^{6}$ under the accelerating voltage of 40 to $100 \mathrm{kV}$ (JEOL, Peabody, Mass, USA). Samples were prepared by placing $1.0 \mu \mathrm{L}$ of the Ag-NPs solution in ultrathin carbon film/holey carbon 400 mesh copper TEM grids (01824, Ted Pella, Inc., Redding, Calif, USA) and allowing the solvent to evaporate at room temperature. The grids were kept in desiccator to provide a dust-free environment. Raman experiments were done using a Raman Microspectrometer, model RM-2000, CCD camera, Leica LX microscope, $532 \mathrm{~nm}$ laser line, 10$50 \mathrm{~s}$ exposure time, 3 accumulations and a 10x objective lens in a spectra range of $100-3000 \mathrm{~cm}^{-1}$ (Renishaw Inc., Hoffman Estates, Ill, USA). White light microscopy images of samples were acquired in order to determine the content of the sample. An Olympus America, Inc. (Center Valley, Pa, USA) model BH2-UMA high resolution optical microscope designed for mineralogy studies and equipped with 10250x magnification and a 6.0 MB PAX-Cam image capturing CCD camera controlled by PAX-it! Software (Midwest Information Systems, Inc., Villa Park, Ill, USA) was used to capture the white light micrographs. Most of the images captured were taken with $10 \mathrm{x}$ and $100 \mathrm{x}$ ultra long working distance objectives. Z-potential and hydrodynamic radius measurements were obtained using a Zetasizer Nano Series (Malvern Instruments Ltd., manufacturer, Worcestershire, $\mathrm{UK})$.

3.2. Data Analysis. All the normal Raman and SERS spectra obtained were analyzed using OPUS software (Bruker Optics, Billerica, Mass, USA) by applying baseline correction to allow a proper tentative assignment of vibrational bands. Spectra were normalized for intensity, laser power and acquisition time (counts $\cdot \mathrm{mW}^{-1} \cdot \mathrm{s}^{-1}$ ).

\section{Results and Discussion}

4.1. Characterization of Ag-NPs. Borohydride reducedcitrate capped Ag NPs suspensions had a yellowish color when present in an atomic silver concentration of $\sim 10^{-4} \mathrm{M}$. The freshly prepared suspensions were slightly alkaline with a $\mathrm{pH}$ of 8.9 and an absorption maximum at $397 \mathrm{~nm}$. The average diameter obtained from many TEM measurements was $19 \pm 3 \mathrm{~nm}$. Ag-NPs reduced with hydroxylamine were obtained after a few seconds and had a grayish-brown color with an atomic $\mathrm{Ag}$ final concentration of $\sim 10^{-3} \mathrm{M}$. The freshly synthesized NPs colloidal suspensions obtained by hydroxylamine reduction were acid with $\mathrm{pH}$ of 5.7 and an absorption maximum at $437 \mathrm{~nm}$. Average particle diameter was $28 \pm 10 \mathrm{~nm}$. Figures 1 (a) and $1(\mathrm{~b})$ show the UV-Vis spectra, the color of freshly prepared sols and the corresponding TEM images of the borohydride and hydroxylamine nanoparticles, respectively.

4.2. Characterization of Biological Samples. Bt was characterized by Gram and Fulton-Schaeffer spore staining techniques. The Gram-staining technique confirmed the presence of Gram-positive bacillus strain (Figure 2). Endospores staining was performed to establish the presence of vegetative cells and endospores in the sample. Figures 2(a) and 2(b) show vegetative cells or/and endospores content of $B t$ strain used in the experiments under the white light microscope. Previous experiments were used to determine the samples which contained vegetative cells, endospores, and mixtures by a bacterial growth curve (data not shown). The samples used in the Raman/SERS experiments were obtained from the growth stage at $15 \mathrm{hr}$ in which vegetative cells and endospores coexist as mixtures.

4.3. Raman and SERS Experiments. Silver nanoparticles have a plasmon resonance in the visible (VIS) region (400$700 \mathrm{~nm}$ ) of the electromagnetic spectrum with excellent match with laser lines located at 514.5 and $488 \mathrm{~nm}$ and solid-state diode laser at $532 \mathrm{~nm}$. [24] However, by using the excitation lines located at 633 and $785 \mathrm{~nm}$ will be far away from the transverse plasmon band of the silver nano-particles prepared in this research. This fact will have a small contribution to the electromagnetic SERS effect. Biological samples presents a highly fluorescence effect that should be quenched before obtain the SERS 

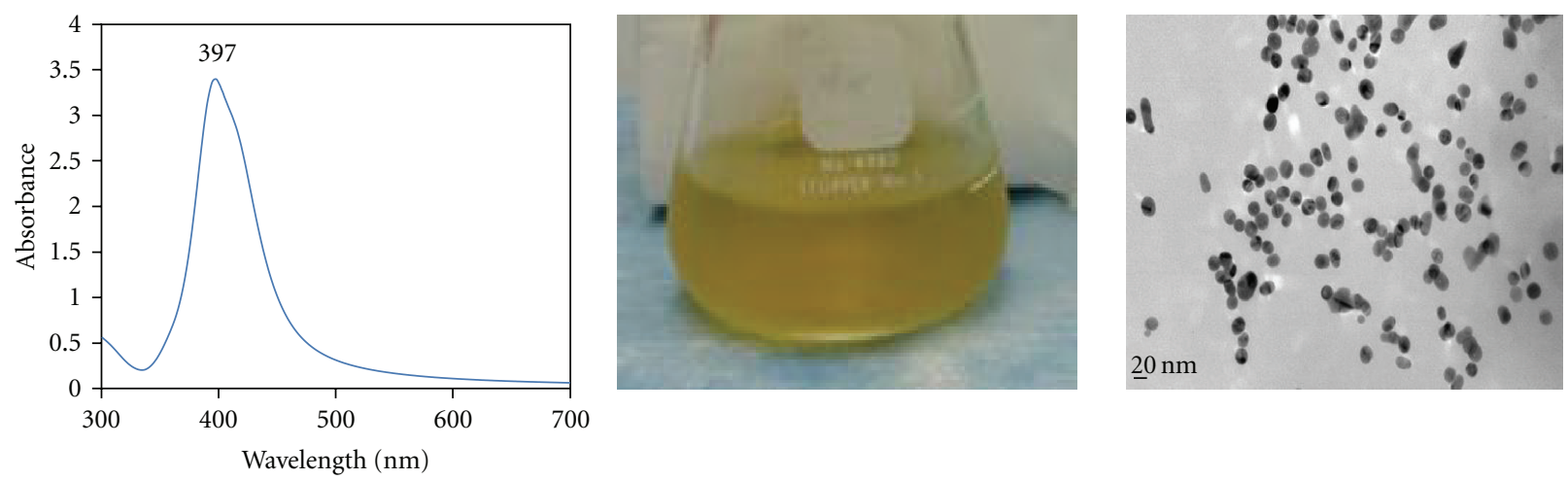

(a)
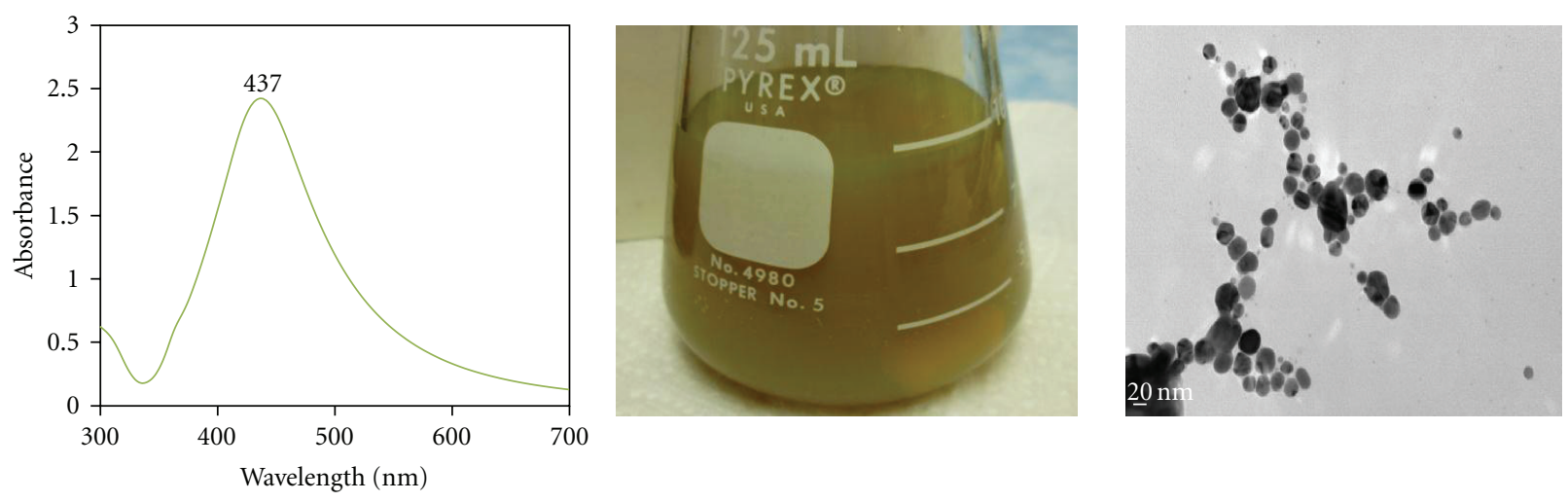

(b)

FIGURE 1: UV-Vis spectra (left), final color of freshly prepared sols (center) and TEM images (right) of: (a) borohydride reduced-citrate capped Ag NPs and (b) hydroxylamine reduced Ag-NPs used in the experiments described.

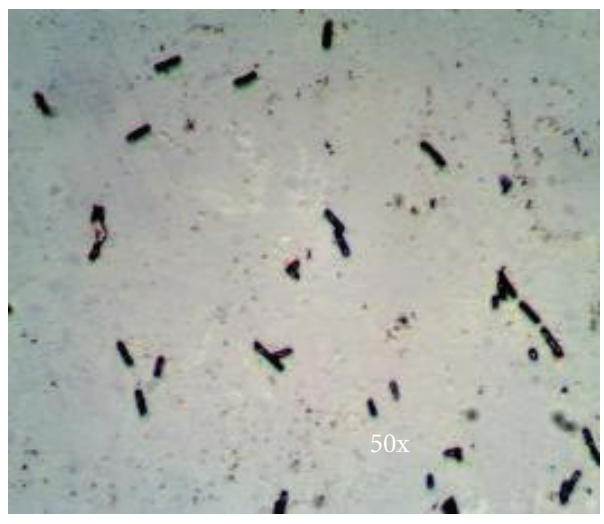

(a)

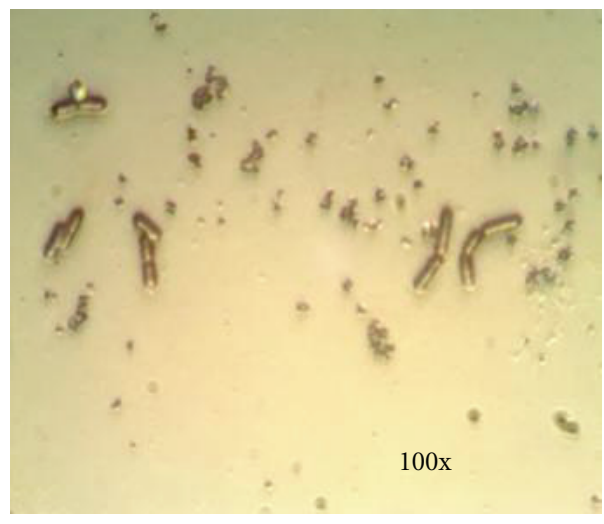

(b)

FIGURE 2: White light micrographs of $B t$ characterization at $15 \mathrm{hr}$ of bacterial growth (a) 50x Gram staining (purple: Gram +); (b) 100x endospores staining with high magnification image of stained endospores.

spectra to obtain good SERS results. As mentioned in previous literature, the fluorescence of bacteria is "especially strong with 532-nm excitation, but some photobleaching is required even for near-infrared (NIR) excitation." [25] In this study, 10 to $50 \mathrm{~s}$ of exposure time were used to minimize the fluorescence problems of the biological samples.
The Raman spectrum of $B t$ at $15 \mathrm{hr}$ of bacterial growth was contaminated with fluorescence from the presence of fluorophores commonly found in many biological compounds. However, important signals could be tentatively assigned from spectra acquired of a highly concentrated bacterial suspension (Figure 3) even though many of them appeared as low-intensity bands in a highly congested background. 


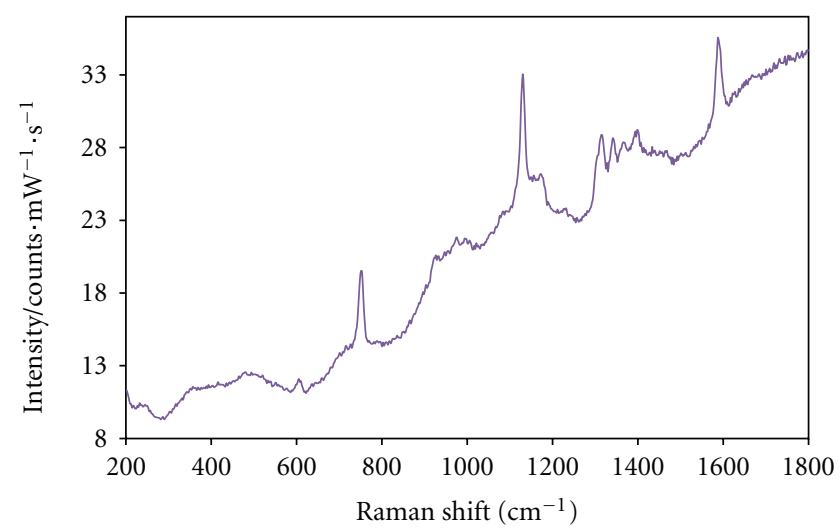

FiguRE 3: Raman spectrum of concentrated sample of $B t$ suspended in $0.1 \mathrm{M} \mathrm{NaCl}$ at $15 \mathrm{hr}$ of bacterial growth.

Several of the bands observed were from glycosidic ring of NAG and NAM at $753 \mathrm{~cm}^{-1}, \mathrm{C}-\mathrm{N}$ and $\mathrm{C}-\mathrm{C}$ stretching at $1130 \mathrm{~cm}^{-1}$, signals from lipid content, $=\mathrm{C}-\mathrm{C}=$ at $1144 \mathrm{~cm}^{-1}$ and $\mathrm{C}=\mathrm{C}$ at $1588 \mathrm{~cm}^{-1}$. Most of the signals observed are related to calcium dipicolinate (CaDPA), which is the main component of the protective layers of the central core cell, the endospores [26]. To enhance the signal identification of the biological content and decrease the fluorescence of the bacterial content several aspects of the biomolecular system under study had to be taken into account. To begin with, SERS spectra in these systems result from the interaction of the metal NPs surface with the outer coating content of the cells. Due to poor signal definition and limited chemical information in the Raman spectrum of $B t$, the volume and concentration of the NPs colloidal suspensions used, the sample amount and concentration of the biological system under study analyzed, the charge of the layer of NPs and the aggregation induction effects of the colloidal NPs had to be optimized. The affinity of the biomolecular sample $(B t)$ to Ag-NPs was improved resulting in enhancement of the signal to noise of the SERS spectra obtained. Also, a significant decrease in fluorescence present in the Raman spectra of this bacillus was observed. Details of these effects are clearly discussed in the next sections with dealing with Ag-NPs reduced by borohydride and hydroxylamine.

4.3.1. Borohydride-Reduced Ag-NPs. The SERS spectra shown in Figure 4 clearly demonstrate the high signal enhancement of the vibrational modes of $B t$ when using borohydride reduced metallic suspension of NPs as SERS substrates. These small Ag-NPs have been used to successfully detect bacterial samples $[13,15,17]$. The biochemical composition of this bacillus sample could be identified mostly by the calcium dipicolinate (CaDPA) peaks that dominate the spore content among other bacterial wall content. The SERS spectrum of Bt (Figure 4(a)) has characteristic peaks that can be tentatively assigned based on literature values as shown in Table $1[10,27,28]$. The affinity of these nanoparticles to Bt can be increased by a slight aggregation of NPs [17] and by surface charge modification of the NPs when a biosample that does not induce any aggregation is been used [16]. The
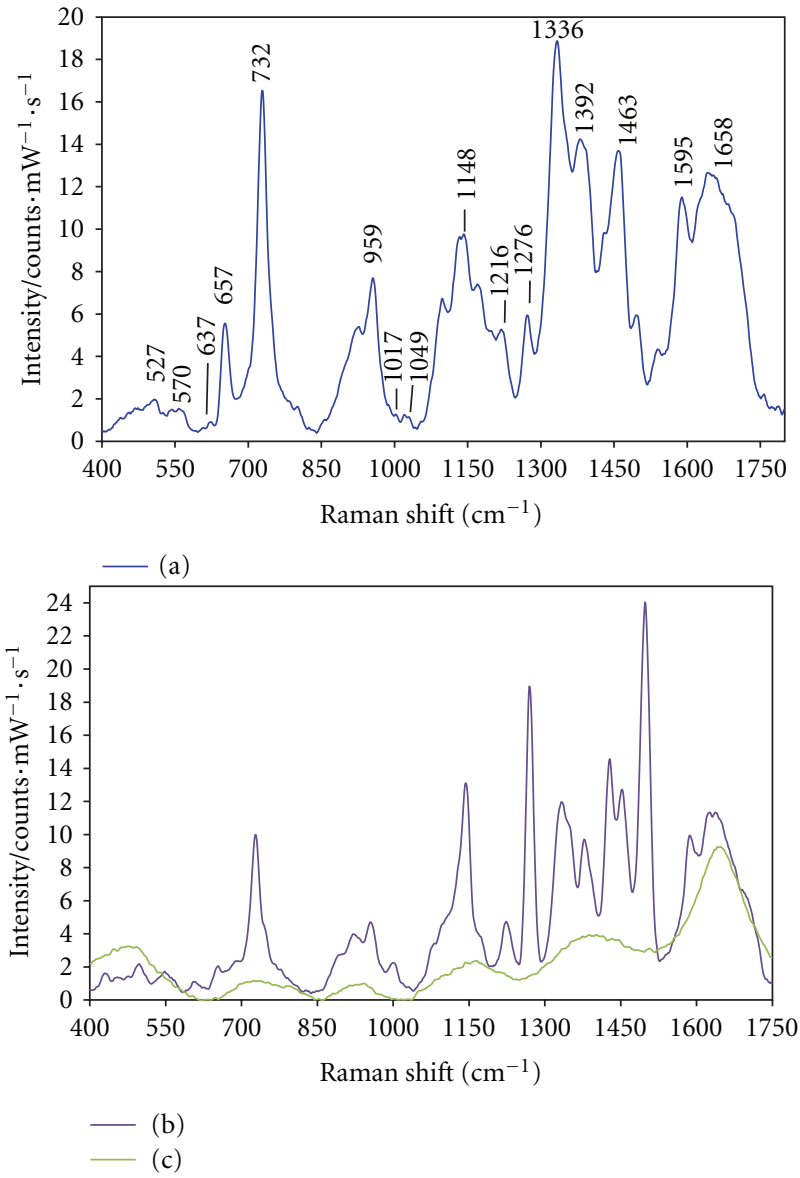

Figure 4: Enhanced Raman spectra of Bt and Ag-NPs: (a) Spectrum of $B t$ suspended in $0.1 \mathrm{M} \mathrm{NaCl}$ at $15 \mathrm{hr}$ of bacterial growth in contact with citrate capped borohydride reduced Ag-NPs; (b) Spectrum of $B t$ using chloride anion $(1.0 \mathrm{M}, \mathrm{NaCl})$ as aggregation agent for Ag-NPs; (c) Spectrum of borohydride reduced Ag-NPs aggregated by chloride anion $(1.0 \mathrm{M}, \mathrm{NaCl})$ without microorganisms.

use of aggregation agents at low concentrations, such as chloride, with borohydride-reduced NPs and biomolecular compounds [29] has been used to distribute the nanoparticles on the cell wall obtaining the activation of "hot spots" on the NPs surface [17]. Because the concentration used for aggregation purposes is a critical parameter, high concentrations of the aggregation agent of $1.0 \mathrm{M}$ results in a decrease of the plasmon band of the nanoparticles as shown in Figure 5 and the gray color in Figure 6(c), evidencing the oxidation of the NPs. The agglomeration does not occur uniformly as Ag NPs bind to only certain specific groups on the bacterial cell wall [30] causing a decrease of the close contact of the small NPs to the analyte and as a result a decrease of the SERS signal. The SERS spectrum of $B t$ using nanoparticles aggregated by chloride ions and the Raman spectrum of NPs aggregated by chloride anions (without $B t$ ) can be observed in Figures 4(b) and 4(c), respectively.

However, the lower concentration of $\mathrm{NaCl}$ in which $B t$ was already suspended $(0.1 \mathrm{M})$ can have an influence on the activation of "hot spots" on NPs, inducing a closer, more 
TABLE 1: Tentative assignment of vibrational bands for (a) normal Raman spectrum of $B t$ and SERS spectra of $B t$ using (b) citrate capped borohydride reduced Ag-NPs and (c) hydroxylamine reduced Ag-NPs.

\begin{tabular}{|c|c|c|c|}
\hline Vibration mode & $\mathrm{a}$ & $\begin{array}{c}\mathrm{b} \\
\text { Raman shift } / \mathrm{cm}^{-1}\end{array}$ & c \\
\hline S-S stretching of cysteine in spore coat & & 527 & 526 \\
\hline \multirow{2}{*}{ C-C skeletal of carbohydrates } & & 570 & 587 \\
\hline & & 1049 & 1065 \\
\hline C-S stretching of cysteine in spore coat & & 637 & \\
\hline $\mathrm{N}-\mathrm{H}$ deformation of amide II in CaDPA & & 657 & 657 \\
\hline glycosidic ring of NAG and NAM & 753 & 732 & 728 \\
\hline $\mathrm{C}=\mathrm{C}$ deformation of tyrosine & & 959 & 962 \\
\hline $\mathrm{C}-\mathrm{N}$ and $\mathrm{C}-\mathrm{C}$ stretching & 1130 & & \\
\hline $\mathrm{C}-\mathrm{H}$ in plane bending of $\mathrm{CaDPA}$ & & 1017 & \\
\hline$=\mathrm{C}-\mathrm{C}=$ of lipids or $\mathrm{C}-\mathrm{N}$ aromatic in proteins & 1144 & 1148 & 1134 \\
\hline \multirow{2}{*}{ amide III } & & 1216 & 1246 \\
\hline & & 1276 & \\
\hline $\mathrm{C}-\mathrm{NH}_{2}$ stretching of amide II & & 1336 & 1326 \\
\hline $\mathrm{COO}^{-}$stretching in $\mathrm{CaDPA}$ & & 1392 & 1377 \\
\hline C-H deformation of lipids & & 1463 & 1465 \\
\hline $\mathrm{C}=\mathrm{C}$ ring stretching of lipids & 1588 & 1595 & 1590 \\
\hline amide I & & 1658 & 1705 \\
\hline
\end{tabular}

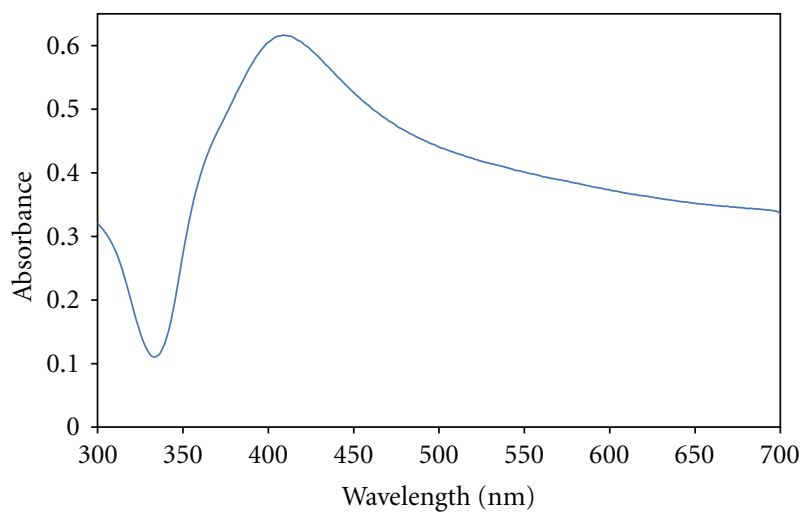

FIGURE 5: UV-Vis spectrum showing the decrease of the plasmon band when borohydride reduced Ag-NPs were aggregated with $\mathrm{NaCl}$ 1.0 M.

effective interaction with biological samples and consequently increasing SERS signals as shown in Figure 4(a). It is advantageous to use the already existing concentration of $\mathrm{NaCl}$ instead of using the bacterial sample suspended in water (washing away the salt) or adding a higher concentra tion of $\mathrm{NaCl}$ as aggregating agent to increase the SERS enhancement effect. This was confirmed with slightly change in the color when $B t$ is added to the Ag-NPs (Figures 6(a), and $6(\mathrm{~b}))$.

The surface chemistry of Ag-NPs can be altered by adjusting the $\mathrm{pH}$ of the sols and thus promoting adsorption of $B t$ on the SERS active substrates [13-16]. At very low $\mathrm{pH}$ values of the colloidal suspension $(\mathrm{pH}<2)$, the surface charge of the NPs began to be neutralized and at very high
$\mathrm{pH}$ values the Ag colloidal NPs were oxidized resulting in precipitation [12]. At this time, the absorbance of the NPs colloids decreased and the interaction with the bacterial wall became poor. In highly acidic and basic $\mathrm{pH}$ sols were very unstable. NPs decrease in size and precipitated after approximately 2-3 hr. Aggregation of NPs was confirmed by the values of hydrodynamic radii (nm): 17.60, 15.57, 14.64, and 14.50 at $\mathrm{pH}$ of $3,5,7$, and 9 , respectively.

As demonstrated in previous works [15], when the $\mathrm{pH}$ of borohydride reduced colloidal suspension are adjusted to more acidic $\mathrm{pH}$ values with respect of the initial value of $\mathrm{pH}$ $\sim 9$, the slightly negative charged induced by the citrate capping agent become slightly more positive with $\mathrm{H}^{+}$ions added and the zeta potential values are more positive confirming the hypothesis. Biochemical content in the bacterial cell wall is dominated by negatively charged compounds such as phosphates in teichoic acids and carboxylate anions from the dipicolinate complex. Thus, strong electrostatic interactions dominate binding of NPs with the bacterial cell wall content [17]. The positive charge on the NPs surface is appropriate for promoting interaction with $B t$, increasing the SERS effect in the biomolecular system. Figure 7 shows the SERS spectra of NPs upon interaction with bacterial suspension at $\mathrm{pH} 3$, 5,7 , and 9. The number of peaks obtained for the target microorganism is significantly larger and the spectral clarity of SERS spectra of $B t$ interacting with borohydride reduced NPs with $\mathrm{pH}$ adjusted and surface charge modified is noticeably greater. For the SERS spectra obtained at $\mathrm{pH} 5$ to 9 , the bands observed are better defined than at higher values ( $\mathrm{pH}$ 11: data not shown) or at lower values $(\mathrm{pH}=3)$. Although it is expected to have more positive charges on the surface at $\mathrm{pH} 3$ at this $\mathrm{pH}$ the NPs were aggregated to a larger extent and the SERS effect decreased. 


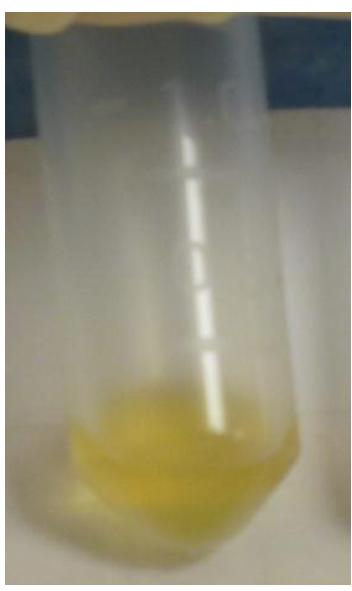

(a)

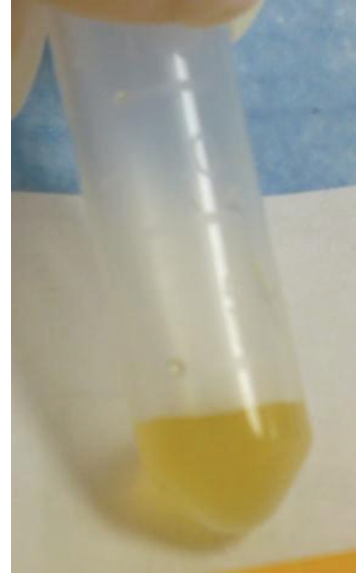

(b)

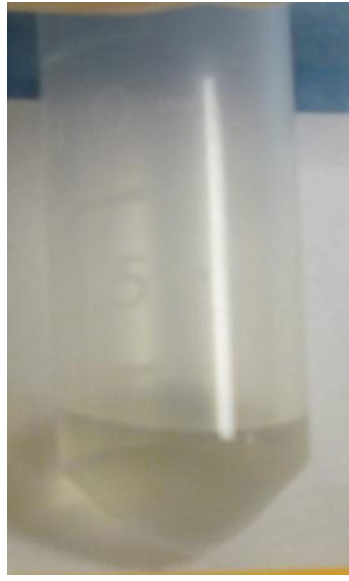

(c)

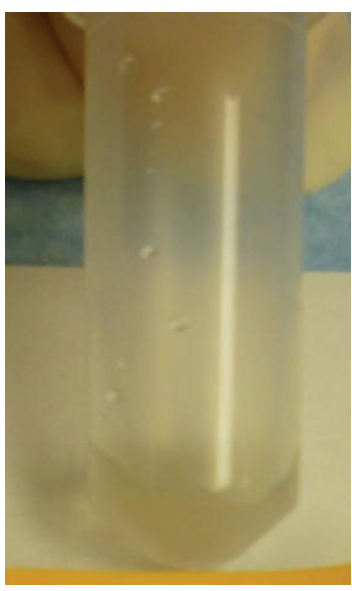

(d)

Figure 6: Changes in color of borohydride reduced Ag-NPs when mixed with bacterial samples and aggregated with NaCl $1.0 \mathrm{M}$. (a) Color of borohydride reduced NPs; (b) Slight change in color when Bt suspended in $0.1 \mathrm{M} \mathrm{NaCl}$ was added to sol; (c) Color of the borohydride reduced Ag-NPs aggregated with $1.0 \mathrm{M} \mathrm{NaCl}$; (d) color of suspensions when $B t$ suspended in $0.1 \mathrm{M} \mathrm{NaCl}$ was added.

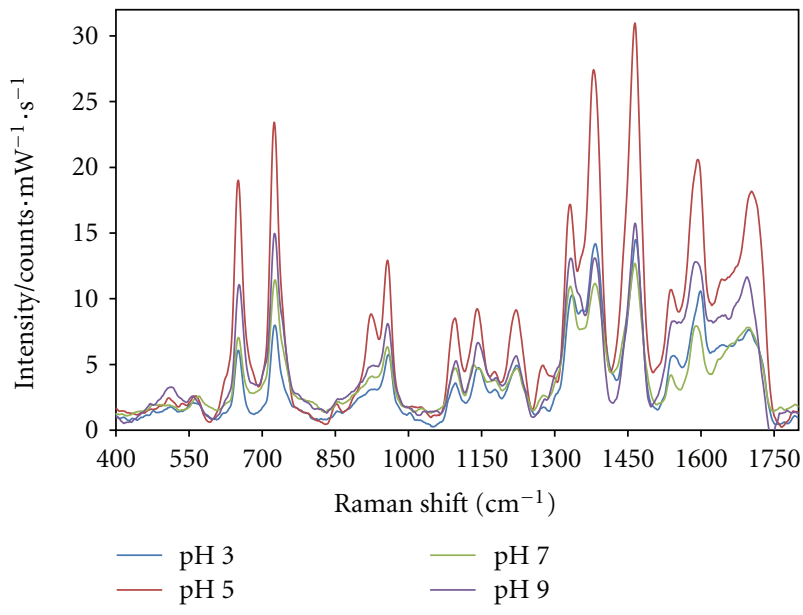

FIGURE 7: SERS spectra of $B t$ in contact with borohydride reduced Ag-NPs at $\mathrm{pH} 3,5,7$, and 9 showing a higher SERS enhancement at pH 5.

4.3.2. Hydroxylamine Nanoparticles. Biochemical components of $B t$ cell wall were identified using NPs-reduced with hydroxylamine hydrochloride. A typical SERS spectrum of the bacterial suspension in contact with NPs (Figure 8(a)) allows the identification of S-S stretching $\left(526 \mathrm{~cm}^{-1}\right)$ and C$\mathrm{S}$ stretching $\left(657 \mathrm{~cm}^{-1}\right)$ of cysteine in spore coat, glycosidic ring of NAG and NAM $\left(728 \mathrm{~cm}^{-1}\right), \mathrm{C}=\mathrm{C}$ deformation of tyrosine $\left(962 \mathrm{~cm}^{-1}\right), \mathrm{C}-\mathrm{C}$ skeletal $\left(587,1065 \mathrm{~cm}^{-1}\right)$ of carbohydrates, $=\mathrm{C}-\mathrm{C}=$ of lipids or $\mathrm{C}-\mathrm{N}$ aromatic in proteins $\left(1134 \mathrm{~cm}^{-1}\right)$, amide III $\left(1246 \mathrm{~cm}^{-1}\right), \mathrm{C}-\mathrm{NH}_{2}$ stretching of amide II $\left(1326 \mathrm{~cm}^{-1}\right), \mathrm{COO}^{-}$stretching in $\mathrm{CaDPA}$ $\left(1377 \mathrm{~cm}^{-1}\right), \mathrm{C}-\mathrm{H}$ deformation of lipids $\left(1465 \mathrm{~cm}^{-1}\right)$, $\mathrm{C}=\mathrm{C}$ ring stretching of lipids $\left(1590 \mathrm{~cm}^{-1}\right)$ and amide I $\left(1705 \mathrm{~cm}^{-1}\right)$ which could be tentative assigned based on literature values $[10,27,28]$. The Raman spectrum of the hydroxylamine-reduced NPs is free from anomalous bands that can interfere with the identification of bacterial composition. Attempts of adding high concentrations of chloride ions as aggregator agent failed. The Raman spectrum of the NPs aggregated by chloride anions (Figure 8(c)) is too rich in spectroscopic information above $1160 \mathrm{~cm}^{-1}$ to use it as background Raman spectrum for microorganism studied. The vibrational bands of $B t$ in this region are masked by the vibrational modes of the nanoparticles aggregated by chloride ions, and thus, the bands cannot be properly assigned (Figure 8(b)). However, high and clear intensity vibrational bands before $1100 \mathrm{~cm}^{-1}$ can be properly assigned to bacterial components. Vibrational signals from hydroxylamine hydrochloride reduced NPs at acidic and alkaline $\mathrm{pH}$ values obtained in the SERS spectra interfere with the proper assignment of the vibrational modes of Bt. The high intensity anomalous bands founds on the addition of the aggregating agents and the $\mathrm{pH}$-dependent ionizable functional groups that can undergo dissociation and protonation, depending on bulk solution $\mathrm{pH}$ values, for hydroxylamine-reduced silver colloids was previously explained by Yaffe and Blanch [31] and Kazanci et al. [16], respectively. As a result, no modification in the nanoparticles surface with $\mathrm{pH}$ changes to hydroxylamine reduced NPs were necessary for a successful detection of these bacillus gram-positive bacteria. $\mathrm{NaCl}$ contained in the suspension of bacterial sample was sufficient to activate "hot spots" of the hydroxylamine reduced NPs leading to strong SERS signals that could be used to characterize biochemical composition of $B t$.

\section{Conclusion}

The results presented demonstrate that SERS spectra obtained with Ag-NPs reduced by hydroxylamine and borohydride capped by citrate and were successfully used to spectroscopically characterize Bt. The use of colloidal suspensions of metallic NPs is favorable to enhance the SERS detection 

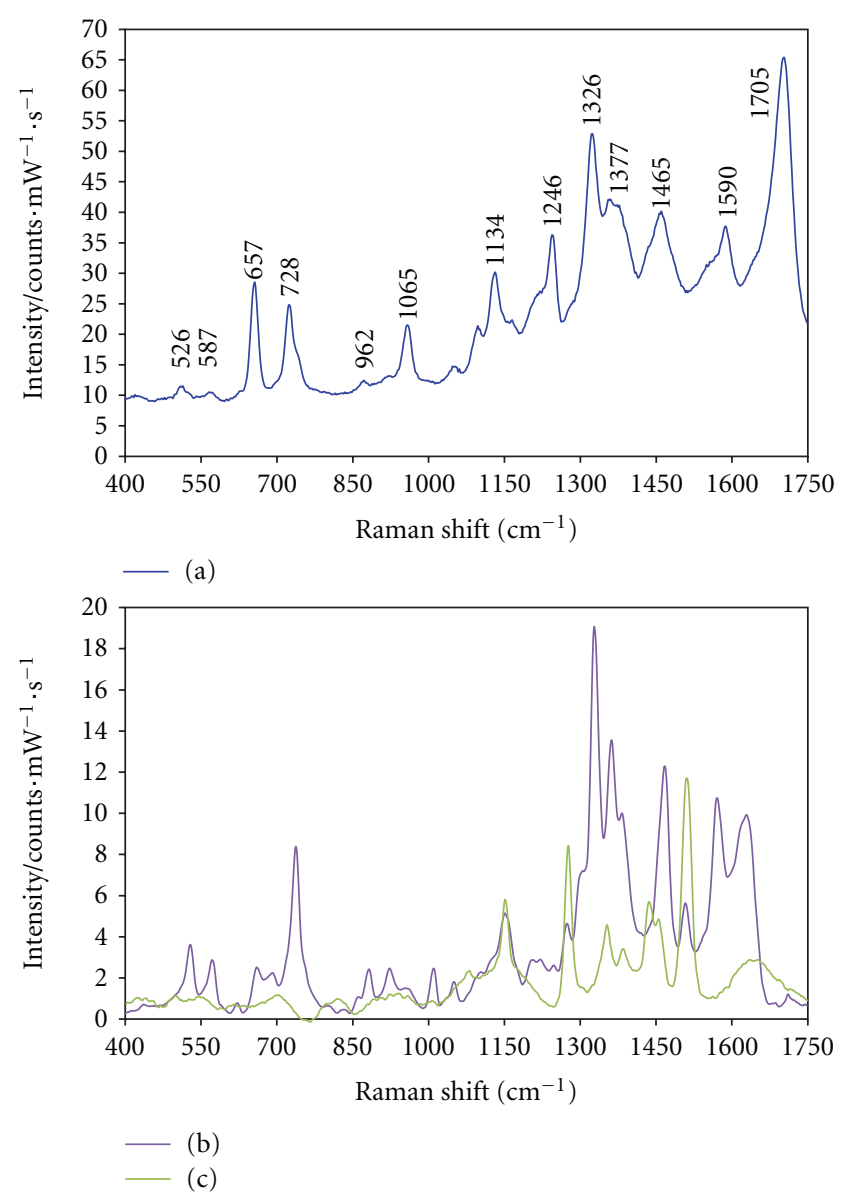

Figure 8: Enhanced Raman spectra of $B t$ and Ag-NPs reduced by hydroxylamine: (a) Spectrum of $B t$ suspended in $0.1 \mathrm{M} \mathrm{NaCl}$ at $15 \mathrm{hr}$ of bacterial growth in contact with Ag-NPs; (b) Spectrum of $B t$ using chloride anion $(1.0 \mathrm{M}, \mathrm{NaCl})$ as aggregation agent for $\mathrm{Ag}$ NPs; (c) Spectrum of hydroxylamine reduced Ag-NPs aggregated by chloride anion $(1.0 \mathrm{M}, \mathrm{NaCl})$ without microorganisms.

of large biological samples compared to the small size of the nanoparticles, because the electrostatic interactions that dominates the interaction of the NPs and bacterial content can occur around all the biological sample and not on one side as is the case of the Raman vibrational enhancement produced by solid metallic surfaces. The small borohydride nanoparticles used with a slightly activated "hot spots" and $\mathrm{pH}$ surface modifications of the NPs to more acidic $\mathrm{pH}$ values ( 7 to 3 ) than the $\mathrm{pH}$ of nanoparticles synthesis preparation $(\mathrm{pH}$ 9) resulted in good SERS substrates for Bt detection. High concentrations of $\mathrm{NaCl}$, as $1.0 \mathrm{M}$, results in a nanoparticles oxidation and a decrease in the SERS signal. Bacterial samples suspended in low concentrations of $\mathrm{NaCl}(0.1 \mathrm{M})$ and modifications of the borohydride nanoparticles surface in a range of 5 to $9 \mathrm{pH}$ values can improve SERS detection of Bt. As shown in this work, surface modifications of NPs with $\mathrm{pH}$ changes results in more reliable spectral information of $B t$ because neat Raman spectra with the modified NPs were obtained at all $\mathrm{pH}$. Raman spectra obtained from NPs aggregated with $\mathrm{NaCl}$ presented several peaks that interfere with the bacterial identification. Hydroxylamine NPs used as SERS substrates for $B t$ detection resulted in good SERS substrates with a slight activation of "hot spots" using low concentrations of $\mathrm{NaCl}$ in which the bacteria were suspended and no $\mathrm{pH}$ surface modifications of the NPs were required.

Results of SERS spectra of experiments with bacteria in contact with NPs at different $\mathrm{pH}$ values differ significantly from one another in some biomolecules and bacteria, depending on the conditions imposed to the interacting microorganisms and NPs systems. An improved interaction, as judged from higher intensity SERS signals, was obtained for NPs with slightly positive charge surface was in contact with this Gram-positive bacteria $(B t)$ containing the negatively charged phosphate groups of the teichoic acids transverse in peptidoglycan layer and the carboxylic groups in the dipicolinic complex of the exosporium layer of endospores. The results suggest that high signal enhancements from the bacterial cell wall and endospores components of $B t$ can be obtained by tailoring the conditions of SERS experiments. However, SERS effect has to be proven with the Bt protoplast and individual endospore components in order to confirm the content of the biological sample and the assignment of bands obtained from SERS experiments.

\section{Acknowledgments}

Part of the work presented in this study was supported by the U.S. Department of Defense University Research Initiative Multidisciplinary University Research Initiative (URI)MURI Program under grant no. DAAD19-02-1-0257. The authors also acknowledge contributions from Mr. Aaron LaPointe from the Night Vision and Electronic Sensors Directorate, Fort Belvoir, Va, Department of Defense, Dr. Jennifer Becker, MURI Program Manager, Army Research Office, DoD, and Dr. Stephen J. Lee, Chief Scientist, Science and Technology, Office of the Director, Army Research Office/Army Research Laboratory, DoD. Support from the U.S. Department of Homeland Security under Award no. 2008-ST-061-ED0001 is also acknowledged. However, the views and conclusions contained in this paper are those of the authors and should not be considered a representation of the official policies, either expressed or implied, of the U.S. Department of Homeland Security. Thanks are due to Kristina Soto-Feliciano for collaboration in the experiments. Dr. Rong Zhang from Jackson State University is acknowledged for facilitating the TEM images.

\section{References}

[1] K. Maquelin, C. Kirschner, L. P. Choo-Smith et al., "Prospective study of the performance of vibrational spectroscopies for rapid identification of bacterial and fungal pathogens recovered from blood cultures," Journal of Clinical Microbiology, vol. 41, no. 1, pp. 324-329, 2003.

[2] J. Chan, S. Fore, S. Wachsmann-Hogiu, and T. Huser, "Raman spectroscopy and microscopy of individual cells and cellular components," Laser \& Photonics Reviews, vol. 2, no. 5, pp. 325349, 2008. 
[3] R. Jarvis, S. Clarke, and R. Goodacre, "Rapid analysis of microbiological systems using SERS," Surface-Enhanced Raman Scattering, vol. 103, pp. 397-408, 2006.

[4] M. J. Ayora, L. Ballesteros, R. Pérez, A. Rupérez, and J. J. Laserna, "Detection of atmospheric contaminants in aerosols by surface-enhanced Raman spectrometry," Analytica Chimica Acta, vol. 355, no. 1, pp. 15-21, 1997.

[5] D. White, The Physiology and Biochemistry of Prokaryotes, Oxford University Press, New York, NY, USA, 2007.

[6] G. J. Tortora, B. R. Funke, and C. L. Case, Microbiology: An Introduction, Pearson Benjamin Cummings, San Francisco, Calif, USA, 2010.

[7] M. T. Madigan and T. D. Brock, Brock Biology of Microorganisms, Pearson Benjamin Cummings, San Francisco, Calif, USA, 2009.

[8] S. Shanmukh, L. Jones, J. Driskell, Y. Zhao, R. Dluhy, and R. A. Tripp, "Rapid and sensitive detection of respiratory virus molecular signatures using a silver nanorod array SERS substrate," Nano Letters, vol. 6, no. 11, pp. 2630-2636, 2006.

[9] A. Sengupta, N. Brar, and E. J. Davis, "Bioaerosol detection and characterization by surface-enhanced Raman spectroscopy," Journal of Colloid and Interface Science, vol. 309, no. 1, pp. 36-43, 2007.

[10] J. Guicheteau, L. Argue, D. Emge, A. Hyre, M. Jacobson, and S. Christesen, "Bacillus spore classification via surfaceenhanced Raman spectroscopy and principal component analysis," Applied Spectroscopy, vol. 62, no. 3, pp. 267-272, 2008.

[11] R. M. Jarvis, A. Brooker, and R. Goodacre, "Surface-enhanced Raman spectroscopy for bacterial discrimination utilizing a scanning electron microscope with a Raman spectroscopy interface," Analytical Chemistry, vol. 76, no. 17, pp. 5198-5202, 2004.

[12] R. A. Alvarez-Puebla, E. Arceo, P. J. G. Goulet, J. J. Garrido, and R. F. Aroca, "Role of nanoparticle surface charge in surfaceenhanced raman scattering," Journal of Physical Chemistry B, vol. 109, no. 9, pp. 3787-3792, 2005.

[13] A. Sengupta, M. L. Laucks, and E. James Davis, "Surfaceenhanced Raman spectroscopy of bacteria and pollen," Applied Spectroscopy, vol. 59, no. 8, pp. 1016-1023, 2005.

[14] A. Sengupta, M. Mujacic, and E. J. Davis, "Detection of bacteria by surface-enhanced Raman spectroscopy," Analytical and Bioanalytical Chemistry, vol. 386, no. 5, pp. 1379-1386, 2006.

[15] M. Kahraman, M. M. Yazici, F. Sahin, O. F. Bayrak, and M. Culha, "Reproducible surface-enhanced Raman scattering spectra of bacteria on aggregated silver nanoparticles," Applied Spectroscopy, vol. 61, no. 5, pp. 479-485, 2007.

[16] M. Kazanci, J. P. Schulte, C. Douglas, P. Fratzl, D. Pink, and T. Smith-Palmer, "Tuning the surface-enhanced raman scattering effect to different molecular groups by switching the silver colloid solution pH," Applied Spectroscopy, vol. 63, no. 2, pp. 214-223, 2009.

[17] M. Knauer, N. P. Ivleva, R. Niessner, and C. Haisch, "Optimized surface-enhanced Raman scattering (SERS) colloids for the characterization of microorganisms," Analytical Sciences, vol. 26, no. 7, pp. 761-766, 2010.

[18] F. Yan, M. B. Wabuyele, G. D. Griffin, A. A. Vass, and T. Vo-Dinh, "Surface-enhanced Raman scattering, detection of chemical and biological agent simulants," Institute of Electrical and Electronics Engineers Sensors Journal, vol. 5, no. 4, pp. 665670, 2005.

[19] W. R. Premasiri, D. T. Moir, M. S. Klempner, N. Krieger, G. Jones, and L. D. Ziegler, "Characterization of the surface enhanced Raman scattering (SERS) of bacteria," Journal of Physical Chemistry B, vol. 109, no. 1, pp. 312-320, 2005.
[20] F. Yan and T. Vo-Dinh, "Surface-enhanced Raman scattering detection of chemical and biological agents using a portable Raman integrated tunable sensor," Sensors and Actuators B, vol. 121, no. 1, pp. 61-66, 2007.

[21] R. Keir, D. Sadler, and W. E. Smith, "Preparation of stable, reproducible silver colloids for use as surface-enhanced resonance Raman scattering substrates," Applied Spectroscopy, vol. 56, no. 5, pp. 551-559, 2002.

[22] N. Leopold and B. Lendl, "A new method for fast preparation of highly surface-enhanced raman scattering (SERS) active silver colloids at room temperature by reduction of silver nitrate with hydroxylamine hydrochloride," Journal of Physical Chemistry B, vol. 107, no. 24, pp. 5723-5727, 2003.

[23] G. P. Glaspell, C. Zuo, and P. W. Jagodzinski, "Surface enhanced Raman spectroscopy using silver nanoparticles: the effects of particle size and halide ions on aggregation," Journal of Cluster Science, vol. 16, no. 1, pp. 39-51, 2005.

[24] O. M. Primera-Pedrozo, J. I. Jerez-Rozo, E. De La CruzMontoya, T. Luna-Pineda, L. C. Pacheco-Londoño, and S. P. Hernández-Rivera, "Nanotechnology-based detection of explosives and biological agents simulants," Institute of Electrical and Electronics Engineers Sensors Journal, vol. 8, no. 5-6, Article ID 4529211, pp. 963-973, 2008.

[25] J. Guicheteau, S. Christesen, D. Emge, and A. Tripathi, "Bacterial mixture identification using Raman and surface-enhanced Raman chemical imaging," Journal of Raman Spectroscopy, vol. 41, no. 12, pp. 1342-1347, 2010.

[26] H. W. Cheng, W. Q. Luo, G. L. Wen, S. Y. Huan, G. L. Shen, and R. Q. Yu, "Surface-enhanced Raman scattering based detection of bacterial biomarker and potential surface reaction species," Analyst, vol. 135, no. 11, pp. 2993-3001, 2010.

[27] J. De Gelder, P. Scheldeman, K. Leus et al., "Raman spectroscopic study of bacterial endospores," Analytical and Bioanalytical Chemistry, vol. 389, no. 7-8, pp. 2143-2151, 2007.

[28] J. L. Chalmers and P. R. Griffiths, Eds., Handbook of Vibrational Spectroscopy, John Wiley \& Sons, New York, NY, USA, 2002.

[29] S. Sanchez-Cortes and J. V. Garcia-Ramos, "Anomalous Raman bands appearing in surface-enhanced Raman spectra," Journal of Raman Spectroscopy, vol. 29, no. 5, pp. 365-371, 1998.

[30] L. Zeiri, B. V. Bronk, Y. Shabtai, J. Czégé, and S. Efrima, "Silver metal induced surface enhanced Raman of bacteria," Colloids and Surfaces A, vol. 208, no. 1-3, pp. 357-362, 2002.

[31] N. R. Yaffe and E. W. Blanch, "Effects and anomalies that can occur in SERS spectra of biological molecules when using a wide range of aggregating agents for hydroxylamine-reduced and citrate-reduced silver colloids," Vibrational Spectroscopy, vol. 48, no. 2, pp. 196-201, 2008. 


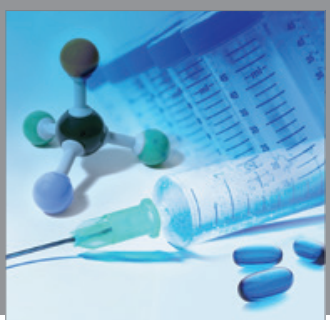

International Journal of

Medicinal Chemistry

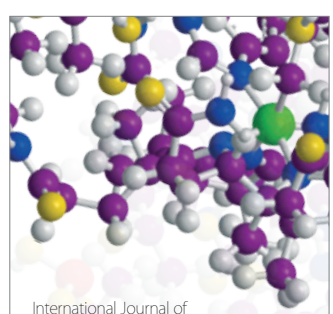

Carbohydrate Chemistry

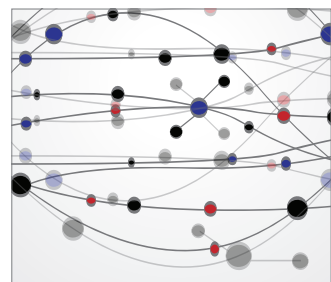

The Scientific World Journal
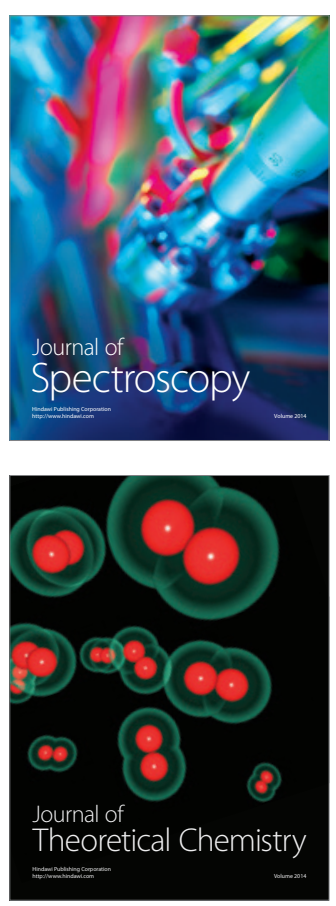
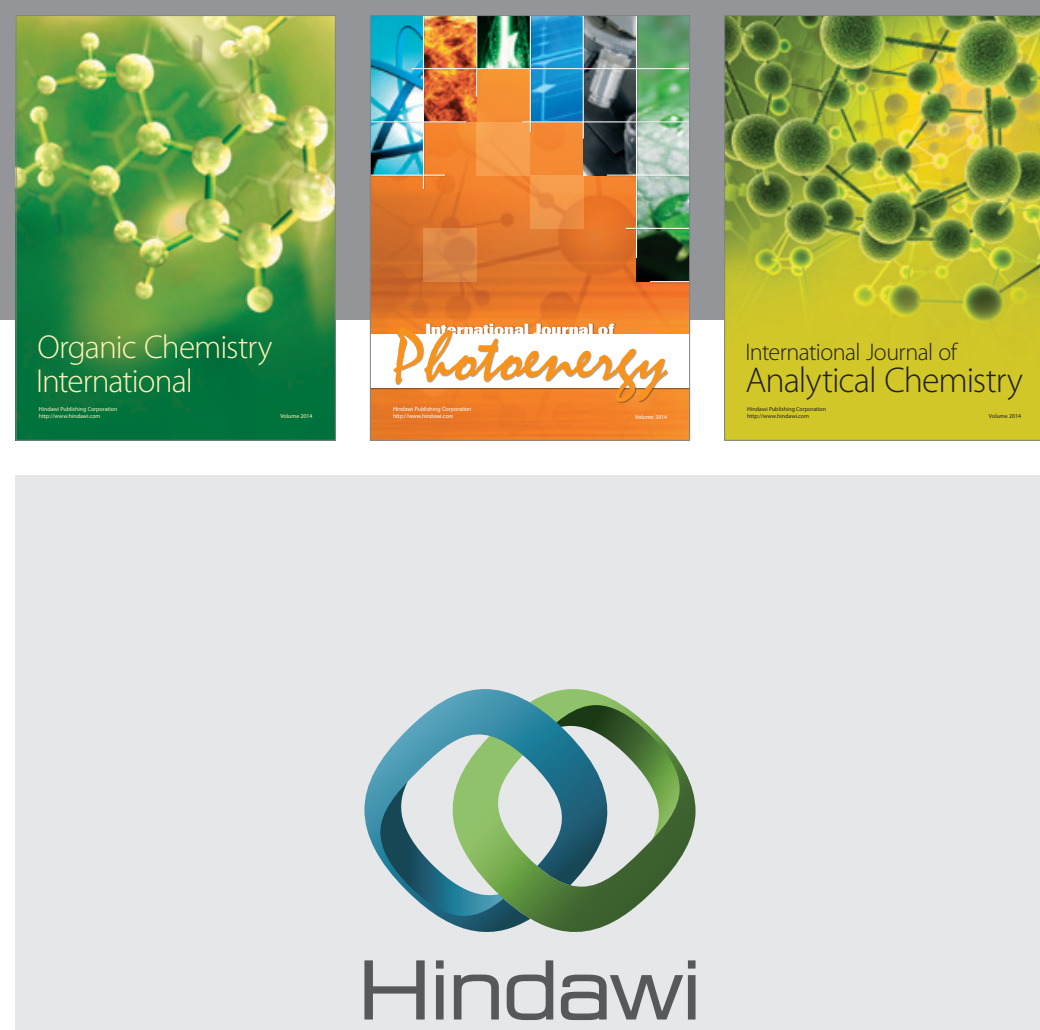

Submit your manuscripts at

http://www.hindawi.com
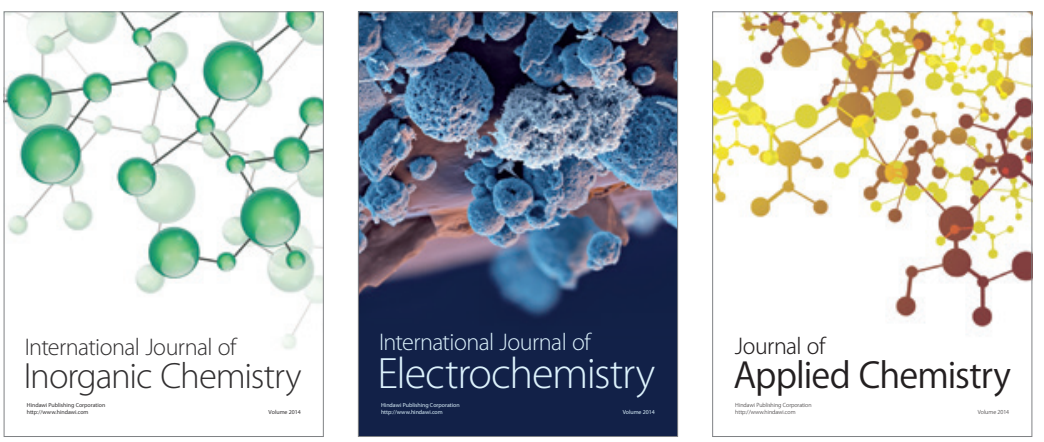

Journal of

Applied Chemistry
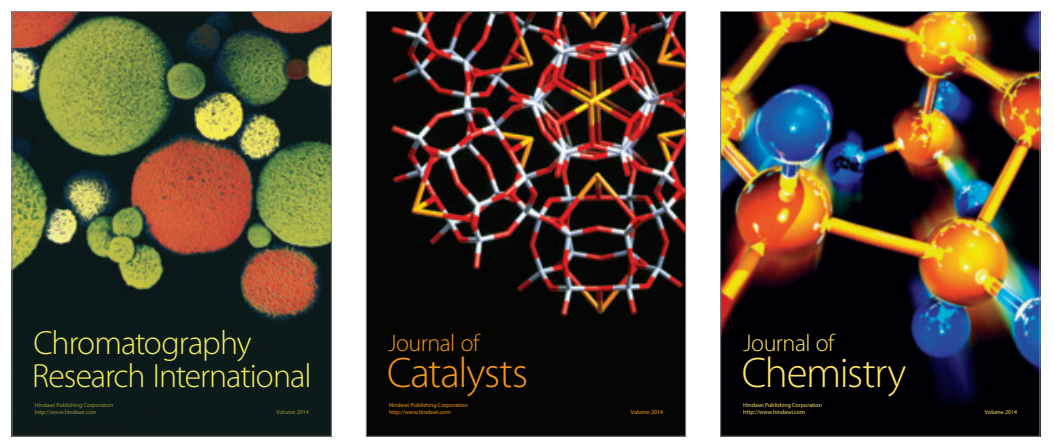
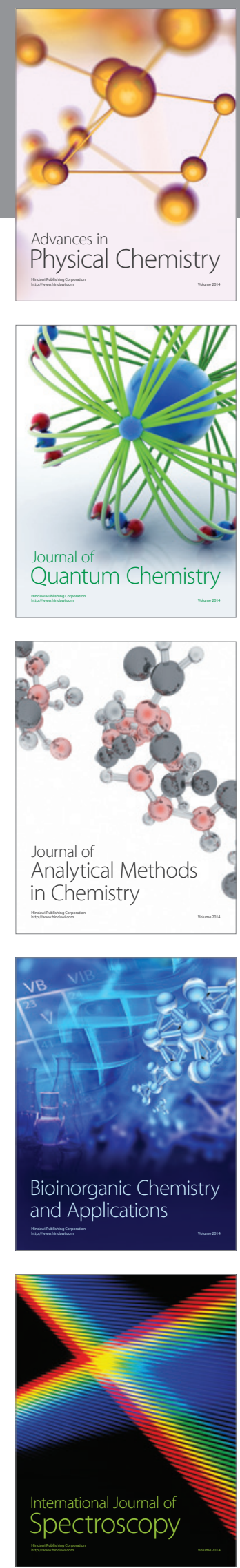